\title{
Precise estimates at municipality level of airborne pollutant emissions due to road traffic
}

\author{
S. Carletti, G. Di Nicola \& G. Passerini \\ Department of Industrial Engineering and Mathematical Sciences, \\ Marche Polytechnic University, Italy
}

\begin{abstract}
In Central Italy, road traffic emissions of airborne pollutants (i.e. Corinair Group 7) account for more than $50 \%$ of overall emissions. The principal pollutants emitted into the atmosphere by cars and trucks are: particulate matter (PM, PM10, and PM2.5), Nitrogen oxides (NOx), Volatile Organic Compounds (VOC) and Carbon monoxide (CO). For this kind of emissions, emission estimate is the only way to assess local impact. Unfortunately, precise estimates at small scales (e.g. county or municipality) rely upon the knowledge of several data such as number and type of vehicles, road transits, fuel consumption etc. detailed for the same scale. Such data are difficult to collect (almost impossible for transits) and update. Moreover, car leasing, national and local polices, and taxex force several people to possess and drive cars that are namely registered and licensed elsewhere. Nevertheless, assessing emission contributions of the various vehicle classes at township level becomes crucial to implement proper limitation policies and regulations. The aim of this study is to compare different methods able to disaggregate airborne pollutant emissions using different proxy variables (e.g. population, number of vehicles, and car registrations) to allow a routinely estimate at local level based on the regional emission data and reliable and easy-to-obtain proxy variables. We analyzed mobility and vehicles of the Marche Region to calculate emissions for the year 2010 using COPERT 4 (COmputer Programme to estimate Emissions from Road Traffic), the choice methodology indicated by the EMEP/CORINAIR Emission Inventory Guidebook. The emissions were estimated at regional level (NUTS2) and provincial level (NUTS3) and we checked several methodologies to allow an accurate estimate at township level.
\end{abstract}

Keywords: PM10, urban air pollution, road vehicle, proxy variable. 


\section{Introduction}

To perform air pollution modeling and assessment, it is necessary to identify pollution sources and quantify their emissions. This crucial first step is often performed through emission estimate that usually requires a bunch of input data. For instance, almost all the features of the studied territory must be considered since even parameters such as geographic location, altitude, and climatic zone, have an impact on emissions (not only those due to air conditioning and heating). On the other hand, levels of urbanization and industrialization affect traffic emissions, both passenger and freight, and emissions from manufacturing processes. For these reasons we need and prepare high-resolution local inventories, which are, each one, characteristic of its area. The inventories can be achieved either through top-down methodology or bottom-up methodology. The second one is more complex and requires a greater number of input data. In 2005, the Marche Region has compiled its inventory using, where possible, the bottom-up methodology. The results can be summarized in Fig. 1, which represents the incidence of main source sectors, according to Corinair/SNAP97 nomenclature, for main airborne pollutants in Marche region. Fig. 2 shows the same data at national level and for the same year $[1,2]$.

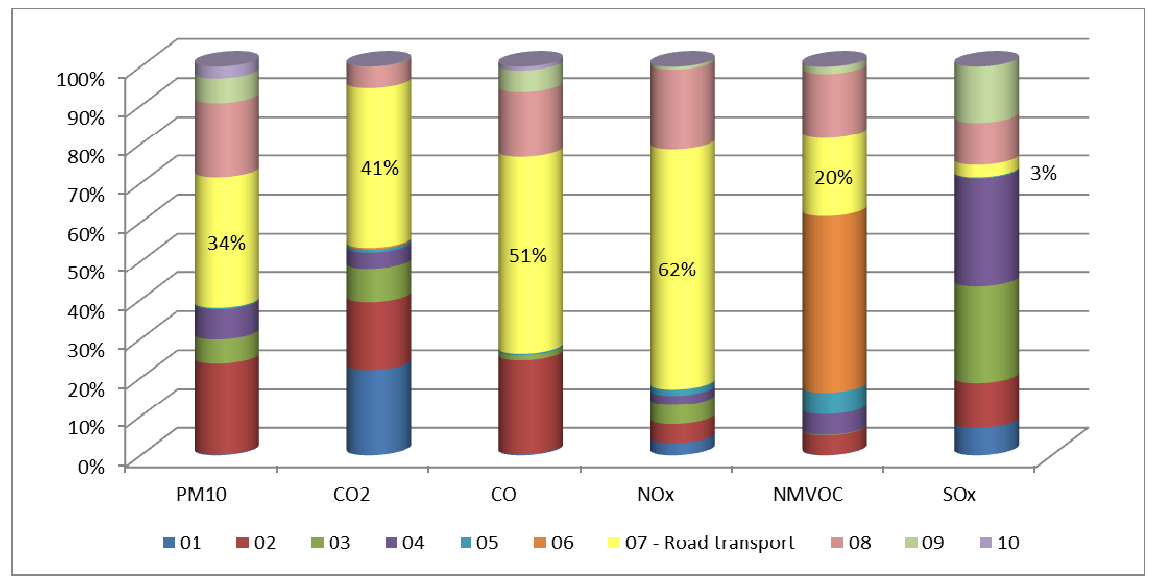

Figure 1: $\quad$ Contribution of main Corinair/SNAP groups to airborne pollutant emissions of selected pollutants in Marche region (Marche Regional Authority, 2005).

The group 7, road transport, is the main source of almost all the airborne pollutants. On a local scale we can focus on particulate matter (PM10), carbon monoxide (CO) and nitrogen oxides $\left(\mathrm{NO}_{\mathrm{X}}\right)$. Emissions of non-methane volatile organic compounds (NMVOC) from group 7 originate mainly from gasoline vehicles, both passenger cars and motorcycles. This requires a separate study as we cannot follow the same procedures we implement for other pollutants. According to the CORINAIR top-down approach, the national totals of 


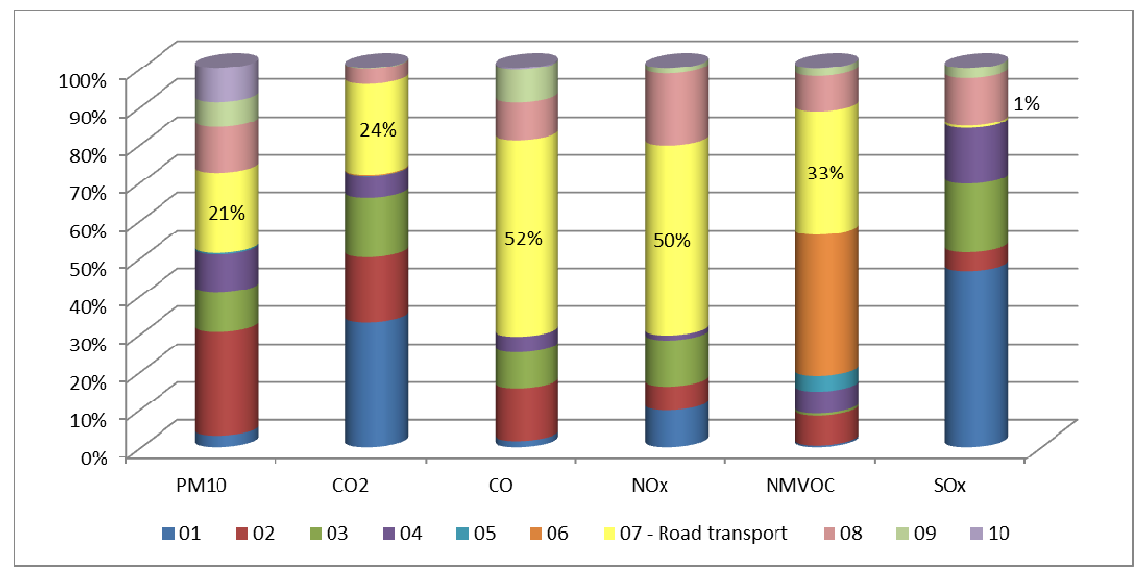

Figure 2: Contribution of Corinair/SNAP groups to airborne pollutant emissions of selected pollutants in Italy (ISPRA-Italy, 2005).

evaporative NMVOC are disaggregated to estimate provincial road transport emissions using the number of gasoline vehicles circulating as proxy [3].

Among the pollutants shown in Figs 1 and 2, the carbon monoxide is now considered a minor problem and the latest legislation for gasoline and diesel motor classes focus on PM and VOC. The Euro 5 and Euro 6 legislation classes for diesel passenger cars enforce a reduction of $28 \%$ and $68 \%$ respectively in $\mathrm{NO}_{\mathrm{X}}$ emissions and a reduction of $88 \%$ in PM emissions compared to Euro 4 emissions. Aim of this study is to compare different methods able to disaggregate airborne pollutant emissions using different proxy variables. We will focus on particulate matter since this pollutant is most often employed to assess ambient air quality. The same proxy variables may be used for nitrogen oxides and therefore the results reflect those of PM10.

\section{Road transport and COPERT}

EMEP/EEA Air Pollutant Emission Inventory Guidebook, within "Exhaust emissions from road transport” Chapter [4], classifies the road vehicles into four categories, based on Corinair/SNAP97 sectors:

- $\quad$ Passenger cars (SNAP 0701);

- $\quad$ Light-duty vehicles $<3.5 t$ (SNAP 0702);

- Heavy-duty vehicles $>3.5 \mathrm{t}$ and buses (SNAP 0703);

- $\quad$ Motorcycles $>50 \mathrm{~cm}^{3}$ (SNAP 0705).

Group 7 emissions can be estimated at different levels of complexity. The Tier 1 method is very simple and applies average fuel-specific emission factors; basically, it requires just the amount of various fuels sold. Tier 2 considers the fuel consumption of different vehicle categories and their emission standards, 
according to emission-control legislation (Euro 1, 2...). Therefore, Tier 2 emission factors are defined in grams per vehicle per kilometer, and these average values are provided for all countries of EU. Tier 3 method is the most complex and precise and is implemented in COPERT 4 [5]. Emissions from road transport are calculated using a combination of emission factors and activity data. The total emissions derives from the sum of hot and cold releases as

$$
E_{T O T}=E_{H O T}+E_{C O L D}
$$

where $E_{H O T}$ are the emissions during stabilized engine operation and $E_{C O L D}$ are emissions during transient thermal engine operation.

Concentrations of some pollutants during the warming-up period are many times higher than during hot operation. The cold-start emissions are attributed mainly to urban, and secondarily to rural driving and are calculated as additional emissions per $\mathrm{km}$. The fraction of mileage driven with a cold engine or the catalyst operated below the light-off temperature depends upon ambient temperature and average trip length $l_{\text {TRIP }}$. In 1990, a value of $12 \mathrm{~km}$ was established for Italy; the introduction of more stringent emission standards for catalyst gasoline vehicles has imposed shorter periods to reach the light-off temperature. We have applied a value of $10.8 \mathrm{~km}$.

For each vehicle category, the number of car registrations in the selected area and total annual kilometers driven are required. For this reason, the use of COPERT is recommended on national territories in order to have enough information and/or a territory quite large to assume that the boundary traffic has little influence compared to vehicles actually registered.

The spatial resolution of an emission inventory often determines which type of approach should be used. A small domain recommends the use of a bottom-up inventory, which evaluates traffic counts, speed recordings and vehicle compositions on several road sections. It should be evident that national emission inventories are difficult to compile in a bottom-up approach. This would require a very large amount of data which can be difficult to find and reconcile for a complete country, or for the regional level (NUTS2). The use the COPERT is recommended in these case.

The bottom-up approach requires traffic counts on each type of road, as well as temporal profiles. Considering the high number of roads that characterize the Italian territory, and in particular the Marche Region, and the different vehicle legislation classes, we have drawn up an inventory for the Region. We tried to apply a top-down approach using different methods to disaggregate airborne pollutant emissions using proxy variables, comparing each other to establish a possible methodology that allows allocating emissions to individual territories in the country, when you have limited information.

\section{Marche emission inventory}

Marche Region is located in central o Italy and the population, at the time of the 2011 census, was 1,542,156. The people who live in cities over 20,000 inhabitants are $45 \%$. There are 173 municipalities out of 239 under 5,000 
inhabitants (22\% of the total population). According to ISTAT data, updated to 2007, the mobility demand amounted to about 739,500 total daily trips; about $75 \%$ remain within regional boundaries, while $35 \%$ of those have origin and destination in the same city. The allocation showed a clear predominance of private transport (on foot, bike, moped, motorcycle, and private car) compared to the public transport, both on road (school bus, coach, bus) and by rail (metro, tram and train).

Italian Automotive Association (ACI) provides the number of registered vehicles for each municipality and the fleet composition at province level [6]. The total number of vehicles in 2010 was 1,326,215; 75\% of the fleet was composed by passenger cars, $47 \%$ of which with gasoline fuel, $39 \%$ with diesel fuel and the remaining with natural gas, LPG (5\%) and CNG (9\%). The light duty vehicles were less than $9 \%$, while heavy duty vehicles and buses constituted more than $2 \%$ of the vehicle fleet.

According to the European Directive 2009/30/EC, starting from 2009, fuels must have specific properties in order to protect human health. Typical values for sulfur content are $40 \mathrm{ppm}$ for gasoline and 8 ppm for diesel [4]. In 2010, the fuel sold in Marche for road transportation accounted for 245,046 tons of gasoline, 512,033 tons of diesel and 32,670 tons of LPG. The value of diesel considers only the petrol stations, and not the wholesale market. For this reason, we decided to consider also a part of the extra-network market.

COPERT methodology estimates emission factors $(\mathrm{g} / \mathrm{km})$ for each pollutant, vehicle category and driving condition. Such factors can be used as input for other models or are used by COPERT to calculate the fuel consumption and the total quantity of each pollutant, by multiplying them for the number of vehicles and their mileage for year. The vehicle mileage is evaluated for different vehicle categories based on road types and vehicle ages [7]. COPERT can be tuned by means of actual fuel statistics (namely fuel sold): high deviations in fuel estimate usually mean a wrong mileage evaluation. A trial-and-error approach allows acceptable estimates of mileage. In this study, such deviations assume values less than $1 \%$.

\begin{tabular}{|l|l|r|r|r|}
\hline \multicolumn{1}{|l|}{ Fuel Balance } \\
\hline & Fuel & \multicolumn{1}{c|}{ Statistical ( $\mathrm{t}$ ) } & \multicolumn{1}{c|}{ Calculated (t) } & \multicolumn{1}{c|}{ Deviation (\%) } \\
\hline & Gasoline (fossil \& bio) & 245046.00 & 243943.33 & -0.45 \\
\hline & Diesel (fossil \& bio) & 749497.00 & 752333.32 & 0.38 \\
\hline & LPG & 32670.00 & 32702.55 & 0.10
\end{tabular}

Figure 3: Fuel balance. ("Statistical" is the fuel sold; "calculated" is the estimated fuel consumption.)

Regarding fuel, between 2005 and 2010 there were few changes in the composition of heavy duty truck and light duty vehicle fleets while major changes happened in passenger car sector: a considerable shift from gasoline to diesel fuel made diesel car percentage rise from $29 \%$ to $39 \%$ in the region. This has led to changes also in terms of emissions (Fig. 4 and Table 1), with greater 


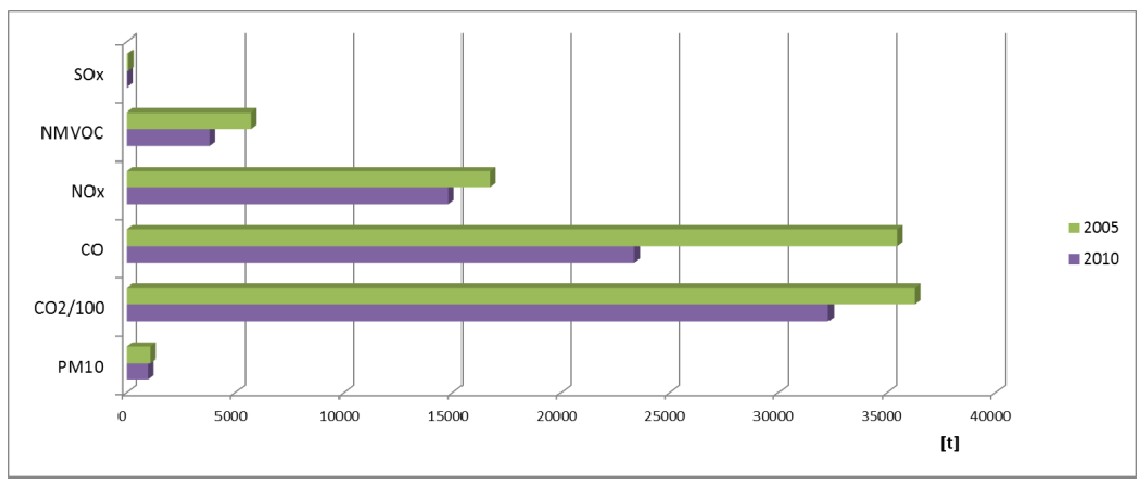

Figure 4: Total emissions of main pollutants in Marche Region. The values of 2005 series are taken from the last Emission Inventory and the 2010 series are the results of COPERT.

reductions of pollutants mainly emitted by gasoline cars, namely NMVOC and CO. Sulfur oxides $\left(\mathrm{SO}_{\mathrm{X}}\right)$ were reduced by reducing the amount of sulfur in fuel.

\section{Gridding}

Gridding of road transport inventories is required when trying to assess local air quality or to have a better allocation of national or regional emissions within particular areas. We calculated the emissions for the whole Marche Region and estimated them for each municipality using several proxy variables, such as the local population and the road network.

Table 1: Total emissions and percentage change of main pollutants in Marche Region.

\begin{tabular}{|l|r|r|}
\hline & $\begin{array}{c}\text { COPERT 2010 } \\
\text { [tons] }\end{array}$ & $\begin{array}{c}\text { Percentage change } \\
\text { between COPERT } \\
\text { 2010 and 2005 } \\
\text { Inventory }\end{array}$ \\
\hline $\mathrm{PM} 10_{\mathrm{CO}}$ & 972 & $-10 \%$ \\
\hline $\mathrm{CO}$ & $3,229,770$ & $-11 \%$ \\
\hline $\mathrm{NO}_{\mathrm{X}}$ & 23,358 & $-34 \%$ \\
\hline $\mathrm{NMVOC}$ & 14,796 & $-11 \%$ \\
\hline $\mathrm{SO}_{\mathrm{X}}$ & 3,827 & $-33 \%$ \\
\hline
\end{tabular}

The method suggested by the Guidebook for the spatial allocation of emissions arising from COPERT, exploits the distinction between driving conditions. Urban emissions are allocated to urban areas in cities with a population greater than 20,000 inhabitants: the proxy variable is the number of 
residents. Rural emissions are distributed all over the countryside outside urban areas: the proxy variable in their area. Highway emissions are allocated to highways only: the proxy variable is the length of such roads.

This method is not useful in the Marche Region that comprises only 15 cities above 20,000 inhabitants (with an average population of about 46,500) and whose population density strongly varies within the territory being rather high all over the coastal zone and almost null in mountain area. For this reason we preferred to use proxy variables independent from the driving condition and/or to allocate urban and rural emissions to the entire municipality areas.

The top-down methodology can be performed by different proxy variables; in this study have been checked the following variables:

1. number of residents within the municipality;

2. number of vehicles registered within the municipality;

3. number of vehicles registered within the municipality and classified by category (passenger cars, light-duty trucks, heavy-duty vehicles, buses, motorcycles, etc.);

4. number of vehicles registered within the municipality and classified by category and by legislation class (euro 1, 2..);

5. length of streets marked in the road network (as for Corinair method); rural emissions are allocated to county roads and secondary truck roads (like B-roads in UK), highway emissions for highway and freeway (dual carriageway roads). Urban emissions are allocated to each municipality according to inhabitants. The road network does not mark the local roads.

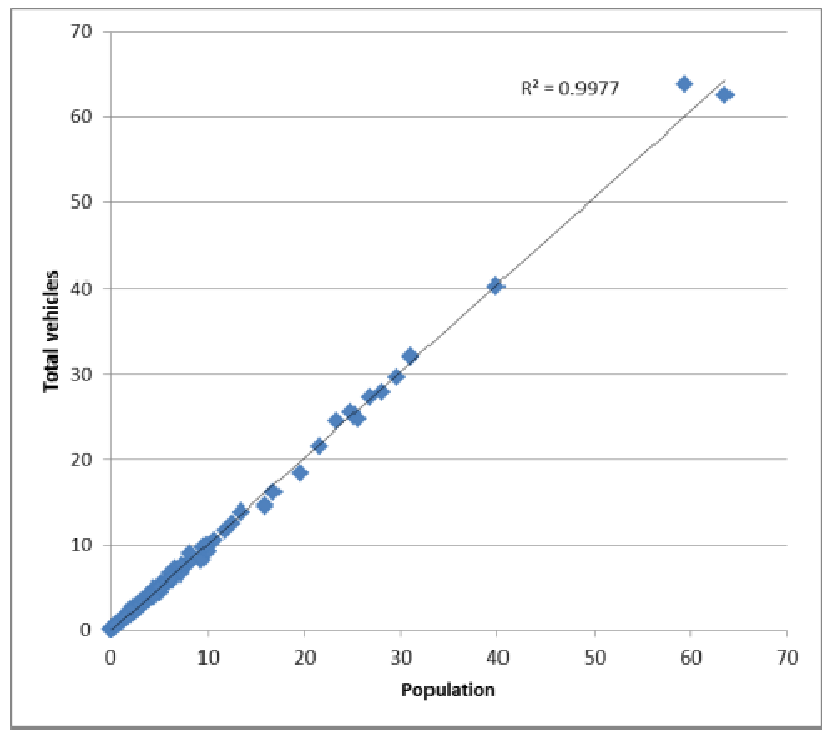

Figure 5: Scattergram and coefficient of determination between the population and the number of total vehicles. 


\section{Results and discussion}

The first two methods in the above scheme provide similar results because the two proxy data, inhabitants and vehicles, have high correlation on municipal basis:

$$
E_{M U N}=E_{R E G} \cdot \frac{N_{M U N}}{N_{R E G}}
$$

In the first methodology $\mathrm{N}$ is the number of inhabitants and in the second is the number of vehicles, including motorcycles. The ratio of total vehicles relative to population in each municipality ranges from 0.72 and 1.11 , and the ratio between cars and population is a number among 0.55 and 0.86 . This is a first important result since this means that using the most accessible proxy variable, the resident population gives a result comparable with the second approach that was considered, in principle, more precise.

Nevertheless, the number of vehicles is a parameter that sum all categories and does not differentiate suitably between more polluting or less polluting vehicles, both for legislation classes and for the annual mileage; namely this method considers in the same way a Euro 1 duty vehicle, a Euro 5 passenger car, or even a motorcycle that runs a few kilometers a year. Fig. 5 shows the scattergram between these two datasets of municipality emissions, and the coefficient of determination $\left(\mathrm{R}^{2}\right)$.

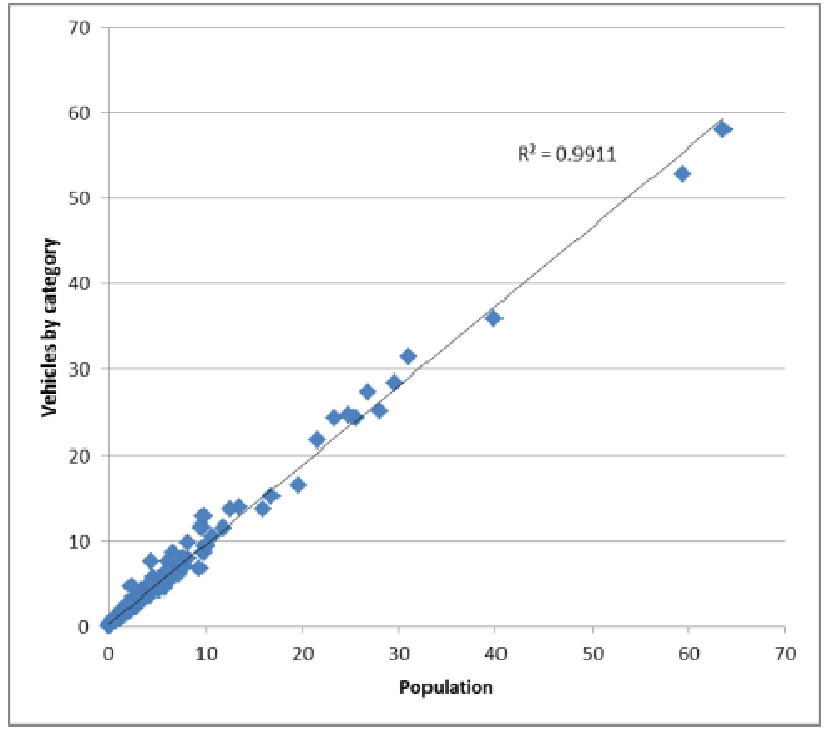

Figure 6: Scattergram and coefficient of determination between the population and the number of vehicles by category. 
The third method classifies by category (passenger cars, light-duty trucks, heavy-duty vehicles, buses, motorcycles) and evaluates emissions at municipality level ( $\mathrm{E}_{\mathrm{MUN}}$ ) by multiplying the regional emission due to a single vehicle category ( $\left.E_{R E G, c a t}\right)$ for the percentage in the municipality of that type of $\operatorname{car}\left(\mathrm{N}_{\mathrm{MUN}, \mathrm{cat}}\right)$ compared to the total $\left(\mathrm{N}_{\mathrm{REG}, \mathrm{cat}}\right)$

$$
E_{M U N}=\sum_{c a t=1}^{5} E_{R E G, c a t} \cdot \frac{N_{M U N, c a t}}{N_{R E G, c a t}}
$$

Even in this case the coefficient of determination is high (Fig.6).

The fourth method makes a more detailed disaggregation, involving the legislation class in addition to the vehicle category. The regional emission due to a single vehicle category and class legislation $\left(E_{R E G, c a t, l e g}\right)$ is multiplied by the percentage in the municipality of that type $\left(\mathrm{N}_{\mathrm{MuN}, \text { cat,leg }}\right)$ compared to the total $\left(\mathrm{N}_{\mathrm{REG}, \text { cat,leg }}\right)$. The sum of each category and legislation class gives the municipal emission:

$$
E_{M U N}=\sum_{c a t=1}^{5} \sum_{\text {leg=1 }}^{6} E_{R E G, c a t, \text { leg }} \cdot \frac{N_{M U N, \text { cat }, \text { leg }}}{N_{R E G, \text { cat }, \text { leg }}}
$$

The fifth method considers the lengths of roads marked in the road network. Rural emissions are allocated to county roads and secondary truck roads (like Broads in UK), highway emissions to highways and freeways (dual carriageway roads), and the urban emissions are allocated to each municipality according to inhabitants. We also checked the methodology suggested by Guidebook for national inventories, similar to the fifth reported here, but with a different allocation between urban and rural emissions.

As a result we have six methods, each one with a different value of municipal PM10 emission. First of all we analyzed the trends of these data series, comparing two at a time. By evaluating the coefficients of determination we noted that the series are highly correlated from a maximum of 0.9999 (between the third and fourth methodology) to 0.9210 (between the second and fifth methodology). For a better analysis, the trends were calculated as the summation of the differences in modulus between the emissions of each municipality. Concurring with the previous results, the highest difference is between the second and fifth methodology, with a value of 337 tons of PM10. A higher value is found when comparing the fifth and sixth methodology, but as mentioned above this is due to a different allocation between urban and rural emissions. In the same way, the lower value is in the comparison between the third and fourth methodology, with a value of 10.81 tonnes. Comparing these values to the regional total, this means that in the first case, $35 \%$ of emissions are distributed differently among the municipalities, while in the second case only $1 \%$.

From Table 2 it is obvious the homogeneity that characterizes the results of the top four methodologies, with almost same values encountered between the third and the fourth. This shows that, for instance, the information entered for the third methodology is already completely adequate. 
Table 2: $\quad$ Coefficient of determination (above the main diagonal) and ratio between summation of the differences in modulus and total emissions (below the main diagonal).

\begin{tabular}{|c|c|c|c|c|c|c|}
\hline & 1 & 2 & 3 & 4 & 5 & 6 \\
\hline 1 & - & 0.9977 & 0.9911 & 0.9917 & 0.9255 & 0.9794 \\
\hline 2 & $4 \%$ & - & 0.9912 & 0.9917 & 0.9210 & 0.9747 \\
\hline 3 & $10 \%$ & $9 \%$ & - & 0.9999 & 0.9322 & 0.9667 \\
\hline 4 & $10 \%$ & $9 \%$ & $1 \%$ & - & 0.9317 & 0.9672 \\
\hline 5 & $34 \%$ & $35 \%$ & $31 \%$ & $31 \%$ & - & 0.9516 \\
\hline 6 & $21 \%$ & $22 \%$ & $27 \%$ & $27 \%$ & $37 \%$ & - \\
\hline
\end{tabular}

The comparison between the second methodology and the third methodology shows more unexpected results: the municipal distribution changes when the emissions are divided by category car instead of considering the total number of vehicles only. In this case the component of the duty vehicles has a high impact: as written above the ratio of passenger cars and inhabitants is comprised between 0.55 and 0.86, at the same time the vehicular age is fairly steady in all municipalities (insomuch the results between third and fourth methodology are quite similar). The third and fourth methodologies smooth the emission peaks of PM10 in the cities with more inhabitants and vehicles, because there are less duty vehicles in relation to their population but more motorcycles and buses.

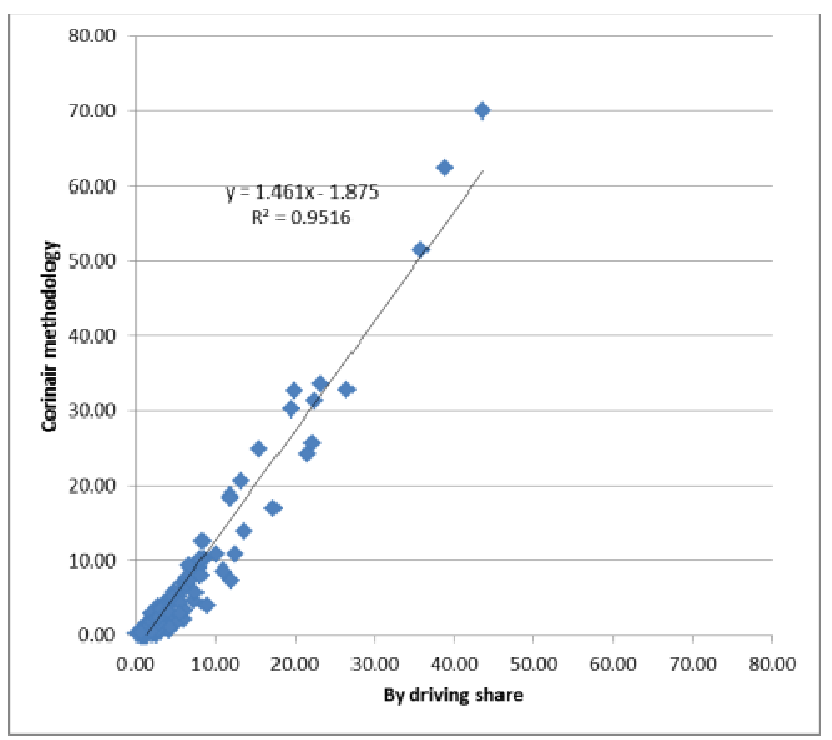

Figure 7: Scattergram and coefficient of determination between the "driving share" method and the methodology suggested by Corinair. 
The fifth and sixth methodologies do not assign the highway contribution to all municipalities so that the percentages of driving share inserted into COPERT become more significant. These two methods of disaggregation differentiate sources of emissions, to help administrators to select the techniques for reducing or limiting traffic. However, they are greatly influenced by driving share and more susceptible to errors and incorrect distributions.

Bar chart for the five top-down methodologies Total amount of PM10 for each municipality [tonnes]

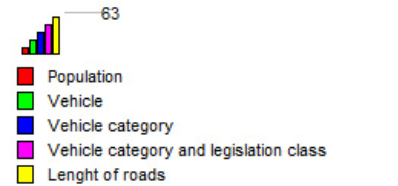

Difference between two top-down methodologies: by vehicle category and legislation class - by lengh of roads [tonnes]

口 2.2 to 13.9

$0 \quad$ to 2.2

$\square-2.2$ to 0

$\square-6.2$ to -2.2

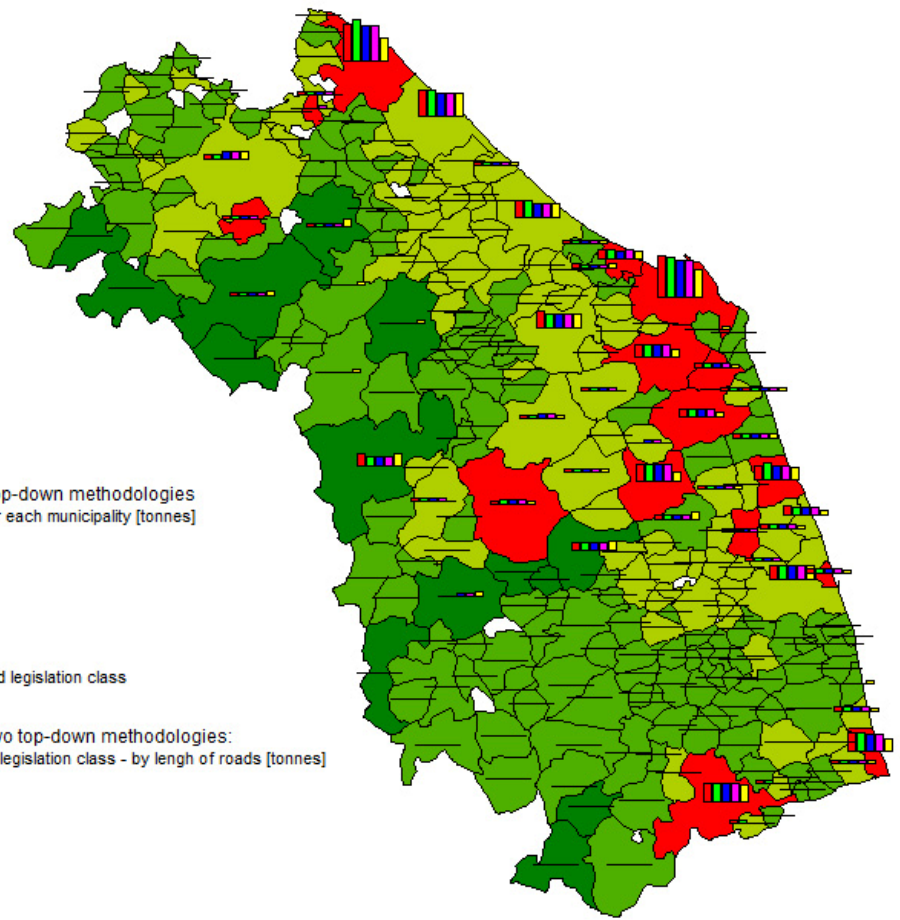

Figure 8: $\quad$ Overall comparison of results (for explanations see the legend).

\section{Conclusions}

The two methodologies of disaggregation that use vehicle counts and inhabitants as proxy variables lead to similar results in the allocation of emissions among municipalities. Often a more detailed level, and thus an increasing number of data to process, does not lead to an improvement in terms of results.

These methods have the disadvantage of relying on static data, which do not consider the actual locations and the real road network. Similarly the last two methods give too much importance to variables inserted into COPERT. These variables are averaged over the whole vehicle fleet and all over the region, and do not consider the particular traffic counts on every street of the road network. This is shown in Figs 7 and 8 when comparing the results. 
For this reason, it is recommended to assign highway traffic only to municipalities actually crossed, and the remaining emissions (rural and urban that account, for about $80 \%$ of emissions the Marche Region) can be distributed with any other static method. The results are strongly correlated when the population or the number of vehicles are proxy variables.

\section{Acknowledgement}

This work has been supported by Fondazione Cariverona of Italy.

\section{References}

[1] ISPRA, La disaggregazione a livello provinciale dell'inventario nazionale delle emissioni, Anni 1990-1995-2000-2005. Rapporti 92/2009, ISBN 97888-448-0392-6.

[2] ISPRA, Trasporto su strada. Inventario nazionale delle emissioni e disaggregazione provinciale. Rapporti 124/2010, ISBN 978-88-448-0466-4.

[3] Saija S., Romano D., A methodology for the estimation of road transport air emissions in urban areas of Italy, Atmospheric Environment, 36, pp. 53775383, 2002.

[4] EMEP/EEA Emission inventory guidebook 2009, Exhaust emissions from road transport, updated June 2010.

[5] Gkatzoflias D., Kouridis C., Ntziachristos L., Samaras Z., COPERT 4 Computer programme to calculate emissions from road transport, European Environment Agency, 2011.

[6] ACI-CENSIS, $X X$ rapporto, 2012.

[7] Caserini S., Giugliano M., Pastorello C., Traffic emission scenarios in Lombardy region in 1998-2015, Science of the Total Environment, 389, pp. 453-465, 2008.

[8] Borrego C., Tchepel O., Barros N., Miranda A.I., Impact of road traffic emissions on air quality of the Lisbon region, Atmospheric Environment, 34, pp. 4683-4690, 2000.

[9] Bellasio R., Bianconi R., Corda G., Cucca P., Emission Inventory for the road transport sector in Sardinia (Italy), Atmospheric Environment, 41, pp.677-691, 2007.

[10] Tuia D., Ossés de Eicker M., Zah R., Osses M., Zarate E., Clappier A., Evaluation of a simplified top-down model for the spatial assessment of hot traffic emissions in mid-sized cities, Atmospheric Environment, 41, pp. 3658-3671, 2007. 